\title{
Threshold in Carcinogenicity of Genotoxic Carcinogens
}

\section{Anna Kakehashi ${ }^{1 *}$, Shoji Fukushima ${ }^{2}$, Min Wei ${ }^{1}$ and Hideki Wanibuchi ${ }^{1}$}

${ }^{1}$ Department of Molecular Pathology, Osaka City University Graduate School of Medicine, Japan

2Japan Bioassay Research Center, Japan Industrial Safety and Health Association, Japan

\begin{abstract}
Nowadays the idea of threshold in the carcinogenicity of chemical carcinogens has attracted interest in the field of carcinogenesis. With genotoxic agents there is considerable experimental evidence in support of the idea. Here, we report on the low dose carcinogenicity in rats observed with heterocyclic amines contained in cooked food, 2-amino-3,8-dimethylimidazo[4,5-f]quinoxaline (MelQx), 2-amino-3- methylimidazo[4,5-f]quinoline (IQ) and 2-amino1-methyl-6-phenylimidazo[4,5-b] pyridine (PhIP), and contaminants of natural and manufactured food products, $\mathrm{N}$-nitrosocompounds such as $\mathrm{N}$-nitrosodiethylamine (DEN) and $\mathrm{N}$-nitrosodimethylamine (DMN). The existence of a no-effect level for MelQx carcinogenicity was confirmed in a medium-term rat liver bioassay. Treatment with increasing doses of MelQx caused sequence of events to occur in the liver tissue: first, the induction of DNA-MelQx adducts at low doses, then an increase of DNA 8-hydroxy-2'-deoxyguanosine (8-OHdG) formation and lacl gene mutations, following by the development of preneoplastic lesions, glutathione S-transferase placental form positive $\left(\mathrm{GST}^{+} \mathrm{P}^{+}\right)$foci, at high doses. In another study, IQ was found to induce preneoplastic lesions in the rat liver at high doses, but lack any effect at low doses. Similarly, examination of carcinogenicity of a well-known colon genotoxic carcinogen PhIP have shown that application at low doses caused the formation of PhIP-DNA adducts, however, a surrogate marker of preneoplastic lesions in the colon, aberrant crypt foci, were detected only at high doses. In studies with N-nitrosocompounds, no GST-P+ foci in the rat livers was detected after the treatment at low doses, on the contrary, at high doses DEN and DMN induced their development. In conclusion, DNA-reactive genotoxic agents such as heterocyclic amines MeIQx, IQ and PhIP, and N-nitrosocompounds DEN and DMN were concluded to exert a threshold, at least practical, with respect to their carcinogenicity.
\end{abstract}

Keywords: Genotoxic carcinogens; Carcinogenic threshold; Heterocyclic amines; N-nitrosocompounds

\section{Introduction}

Chemical carcinogens are divided into two classes, genotoxic and non-genotoxic, on the basis of their ability to react with nuclear DNA and form adducts. In most studies, their effects are experimentally examined when carcinogens are administered at high doses, including the maximum tolerated dose. In the cancer risk assessment, it has been considered that the dose response curve for carcinogenicities of non-genotoxic carcinogens shows a no-response level at low dose, indicating the existence of carcinogenic threshold. However, in case of genotoxic carcinogens, the curve has been always thought to reach zero, indicating that even at low doses there might be a carcinogenic effect. The "non-threshold concept" in the field of risk assessment for genotoxic carcinogens is based on this statement which means the absence of threshold in carcinogenic potential what means that even at very low doses genotoxic carcinogens could have an influence on humans. Nevertheless, this concept appears to be a putative theory, since it is not proved experimentally whether those carcinogens are able to exert carcinogenicity at low doses. Whether it is appropriate or not to extrapolate the effects of exposure at high doses to low doses is still a question of interest. Therefore, it is very important to resolve this concept from the viewpoint of cancer risk assessment and management.

For some chemicals, the initial response constitutes an adaptive effect that maintains homeostasis [1,2]. Disruption of this balance at any level of organization may lead to an adverse effect or toxicity. Adverse or toxic effects produced by genotoxic chemicals often involve chemical reactions with cellular macromolecules (DNA or proteins) and result in disruption of homeostasis. Such effects can be nonreversible at all levels of organization resulting in mutations or inactive protein molecules. Recently biological adaptive responses, resulting in physiological protection have become recognized in radiation carcinogenesis [3]. This concept might be also useful for understanding dose effects in chemical carcinogenesis, since adaptation might be expected in response to low doses of all DNA-damaging agents. Adaptive responses usually involve actions of the chemical on cellular signaling pathways, often receptor mediated, leading to changes in gene expression and metabolism, stimulation of immune response, induction of detoxification and repair systems enzymes and upregulation of tumor suppressor genes. At all levels of organization, adaptive responses are beneficial because they enhance the capacity of organism to respond to chemically induced stress, reversible and preserve viability.

DNA-reactive genotoxic carcinogens, which are mostly mutagenic, are metabolized to ultimate carcinogens and to bind with DNA in target organ cells forming DNA adducts, inducing gene alterations, and exerting carcinogenicity. DNA damage induced by carcinogen is efficiently repaired, however, if the DNA repair errors occur, some of adducts give rise to miss repair, resulting in fixation of mutations and appearance of mutated cells [4]. Apoptosis as well as the DNA repair helps to maintain the normal condition of the tissues and organs. It has been proposed that these events occur during the initiation stage of chemical carcinogenesis. In addition, elevation of cell proliferation and evading apoptosis influences the preneoplastic lesions to develop

*Corresponding author: Anna Kakehashi, Department of Molecular Pathology, Osaka City University Graduate School of Medicine 1-4-3 Asahi-machi, Abeno-Ku, Osaka 545-8585, Japan, Tel: +81-6-6645-3737; Fax: +81-6-6646-3093; E-mail: anna@med.osaka-cu.ac.jp

Received December 05, 2013; Accepted January 24, 2014; Published January 31,2014

Citation: Kakehashi A, Fukushima S, Wei M, Wanibuchi H (2014) Threshold in Carcinogenicity of Genotoxic Carcinogens. J Carcinog Mutagen S3: 006. doi:10.4172/2157-2518.S3-006

Copyright: () 2014 Kakehashi A, et al. This is an open-access article distributed under the terms of the Creative Commons Attribution License, which permits unrestricted use, distribution, and reproduction in any medium, provided the original author and source are credited. 
quickly from mutated cells and to give rise to neoplasms, which are developed in the promotion and progression stages. It is important to mention, that evaluation of DNA adduct levels has become a very good biomarker for exposure assessment [5]. Those included heterocyclic amines (HCAs) MeIQx, IQ and PhIP DNA adducts as well and oxidative DNA damage marker 8-hydroxy-2'-deoxyguanosine (8-OHdG) [6-12].

HCAs are formed during the cooking of meats by condensation of creatinine with amino acids. In recent studies with MeIQx, IQ and PhIP, their content in food was shown to be influenced by numerous factors including temperature, duration and type of thermal processing (grilling, frying etc.), material (beef, pork, poultry, fish, etc.), content of the substrates participating in their synthesis (sugars and amino acids), spices, natural and synthetic antioxidants, $\mathrm{pH}$ and duration of storage of fresh materials prior to processing [13]. In general, the dietary intake of these three HCAs is greatest for PhIP, followed by MeIQx and IQ. It was also reported that considerably more $\mathrm{PhIP}$ is formed in poultry, while more MeIQx is formed in beef, pork and fish [14]. It has been further demonstrated that the heterocyclic aromatic amines in food exist in free and bonded states (bounded to natural polymers, such as proteins, DNA and glycogen) [15]. In the model of the human digestive tract, HCAs are gradually released from their physical and chemical bonds during in vitro digestion of meat. The increase of HCAs content during the digestive process was suggested to be the result of their release under the influence of digestive enzymes like pepsin, endopeptidases trypsin, chymotrypsin and elastase and exopeptidases, which is likely to be catalysed by the temperature and different chemical composition of meat, for example the presence of iron $\mathrm{Fe}^{2+}$ and copper $\mathrm{Cu}^{2+}$ [15].

In this review we survey the examples and report on the carcinogenicities of genotoxic carcinogens at low and high doses which were examined in vivo studies using animal carcinogenesis models from the view point of the carcinogenic mechanism.

\section{Hepatocarcinogenicity and Mutagenicity of 2-Amino- 3,8-dimethylimidazo[4,5-f] quinoxaline (MeIQx)}

MeIQx is one of the most abundant carcinogenic HCAs in cooked foods, speculated to be a human liver carcinogen. MeIQx at doses of 100 to $400 \mathrm{ppm}$ was found to be carcinogenic in the rat liver [7]. It is considered to exert genotoxic activity after metabolic activation by cytochrome P450 isoenzyme CYP1A2 and then N-acetyltransferase (NAT) [16]. Recent studies have shown that MeIQx induces expression of genes encoding metabolic enzymes CYP1A1, CYP1A2 and uridine diphosphate-5'-glucuronosyltransferase type 1A (UGT1A1), and expression of $\mathrm{p} 53$ and its downstream regulated genes cyclin dependent kinase inhibitor 1 (CDKN1A), also known as p21 $1^{\text {WAF1/Cip1 }}$, growth arrest and DNA damage-inducible 45 alpha (GADD45 $\alpha$ ) and apoptosisrelated protein BAX [16].

A summary of recent key in vivo findings obtained in experiments with several genotoxic carcinogens is presented in Table 1 . The effect of MeIQx exposure at different doses was investigated in 1145, 21-dayold male F344 rats. The chemical was administered in the diet at doses of $0,0.001,0.01,0.1,10 \mathrm{ppm}$ (low dose groups) or $100 \mathrm{ppm}$ (high dose group) for 16 and 32 weeks $[17,18]$.The lowest dose $0.001 \mathrm{ppm}$ was established as equivalent to the daily intake of this carcinogen in humans ( 0.2 to $2.6 \mathrm{\alpha g} / \mathrm{man} /$ day). In a 16-week experiment, the total numbers and areas of rat liver glutathione S-transferase placental form positive $\left(\mathrm{GST}-\mathrm{P}^{+}\right)$foci, which are preneoplastic lesions and the end point marker in rat hepatocarcinogenesis, were not changed in the 0.001-1 ppm MeIQx groups, but, at $10 \mathrm{ppm}$ and $100 \mathrm{ppm}$ a trend for an increase and a significant elevation were observed, respectively, as compared to non-treated controls (Figure 1A and Table 1). Furthermore, in 32week study, numbers of GST-P+ foci were significantly increased after the treatment with MeIQx at $10 \mathrm{ppm}$, and particularly at $100 \mathrm{ppm}$ as compared to respective controls (Figure 1A). In addition, the formation of MeIQx-DNA adducts was dose-dependently induced after 4 and 16 weeks of carcinogen application (Figure $1 \mathrm{~B}$ and data not shown, Table 1). Moreover, administration of MeIQx at $1 \mathrm{ppm}$ and higher doses for 4 and 16 weeks caused significant elevation of 8-OHdG levels in nuclear DNA (Figure 1C and data not shown, Table 1).

Similarly, the mutation level of $\mathrm{H}$-ras gene, which role in rat hepatocarcinogenesis is not clear, was significantly increased in the livers of rats administered MeIQx at doses higher than $1 \mathrm{ppm}$ (Table 1) [19]. After the 1-week application of MeIQx in the diet at wide range of doses, $\mathrm{H}$-ras mutation frequency detected by TCEL assay in the rat livers of all groups receiving from $0.001 \mathrm{ppm}$ to $100 \mathrm{ppm}$ dose of MeIQx did not differ from the control value. On the other hand, in the livers of rats treated for 2 weeks, H-ras mutation frequency was elevated in dose-dependent manner, particularly in 10 ppm and 100 ppm MeIQx groups with statistical significance [19].

Next, the mutagenicity of MeIQx in terms of the mutation level of the lacI gene in livers of Big Blue rats with genetic background of F344 was examined [20]. Significant elevation and a marked increase of lacI gene mutation levels was detected after 16 weeks of treatment with MeIQx at a dose of $10 \mathrm{ppm}$ and $100 \mathrm{ppm}$, respectively (Figure 1D and Table 1). From these results, the existence of a no-effect level for the mutagenicity of MeIQx has been demonstrated. Importantly, in MeIQx-treated rats, the formation of GST-P+ foci was significantly induced only at a dose of $100 \mathrm{ppm}$ in line with our previous results (data not shown).

When the initiation activity of MeIQx was examined in a 2-stage carcinogenesis model using 850, 21-day-old male F344 rats with phenobarbital as promoter of hepatocarcinogenesis, GST-P+ foci in the rat livers were significantly increased in the 10 and $100 \mathrm{ppm}$ dose groups, while no difference was found at doses of $1 \mathrm{ppm}$ or less compared to non-treated controls (data not shown) $[18,21]$

Susceptibility to hepatocarcinogenesis varies considerably among different strains of rats. Strain differences may exist in dose-response curve for MeIQx carcinogenicity. For clarification, we compared the effects of low dose MeIQx administration on hepatocarcinogenicity induced BN and F344 rats. Similar results were observed with both rats strains. Low doses (10 ppm and less) of MeIQx had no effect on induction of GST-P ${ }^{+}$foci, although they were significantly increased at high doses (data not shown) [22]

Next, for the evaluation of the hepatocarcinogenicity of concurrent treatment of MeIQx and a typical genotoxic hepatocarcinogen, diethylnitrosamine (DEN), two 16-week rat hepatocarcinogenesis assays were further performed using a total of 790 male F344 rats [23]. In the first study, the effects of concurrent treatment of a subcarcinogenic dose of DEN on rat hepatocarcinogenesis induced by various doses of MeIQx were evaluated. In the second, the hepatocarcinogenicities of combinations of MeIQx and DEN at subcarcinogenic, low carcinogenic and high carcinogenic doses were examined. The concurrent treatment with subcarcinogenic doses of DEN did not enhance MeIQx-induced hepatocarcinogenicity which was evaluated in terms of GST-P+ foci development. Furthermore, concurrent treatment with combinations of subcarcinogenic doses of DEN and MeIQx was not hepatocarcinogenic, indicating that the combined effects of subcarcinogenic doses of DEN and MeIQx were neither additive nor synergistic. In addition, 
A

Number $/ \mathrm{cm}^{2}$

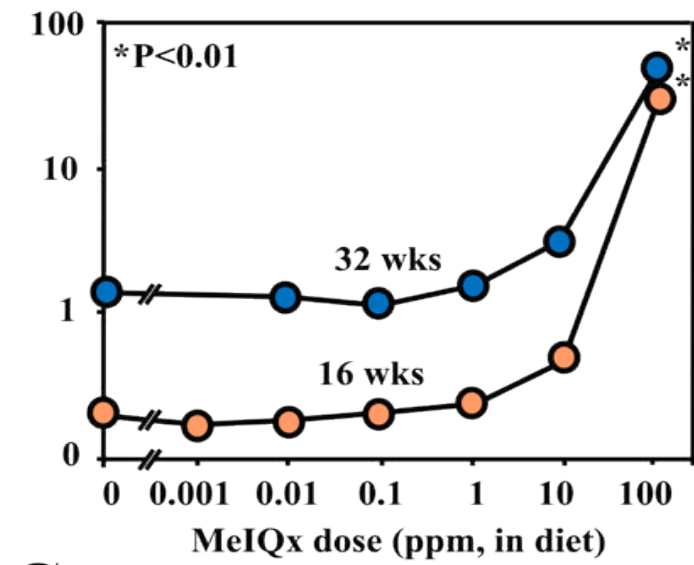

$\mathcal{C}$

8-OHdG

8-OHdG $/ 10^{5} \mathrm{dG}$

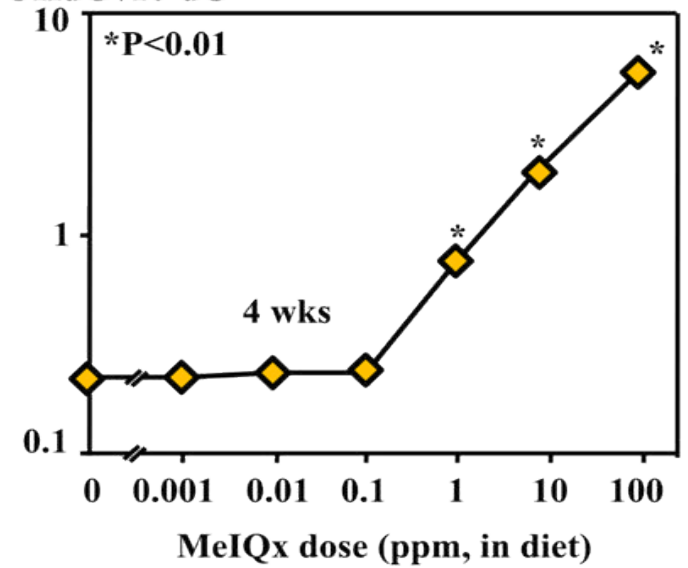

B

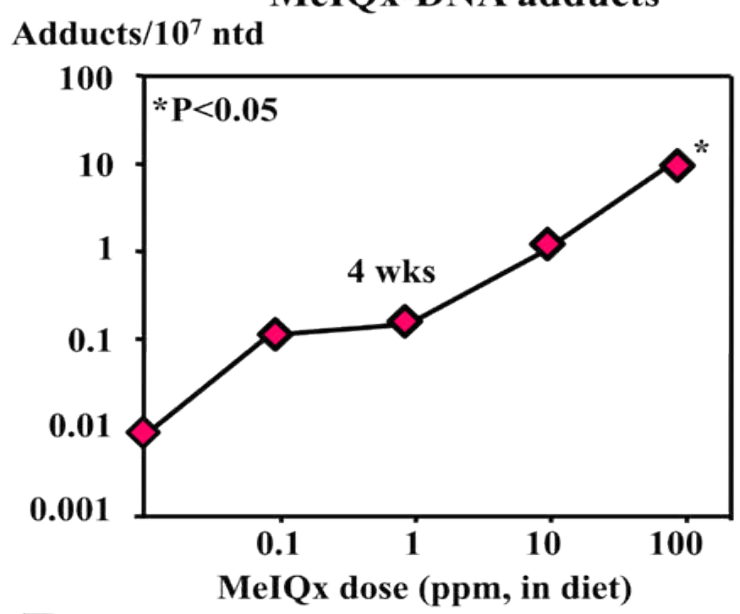

D

\section{Lacl gene mutations}

Incidence $\left(\right.$ No. $\left./ \mathbf{1 0}^{6}\right)$

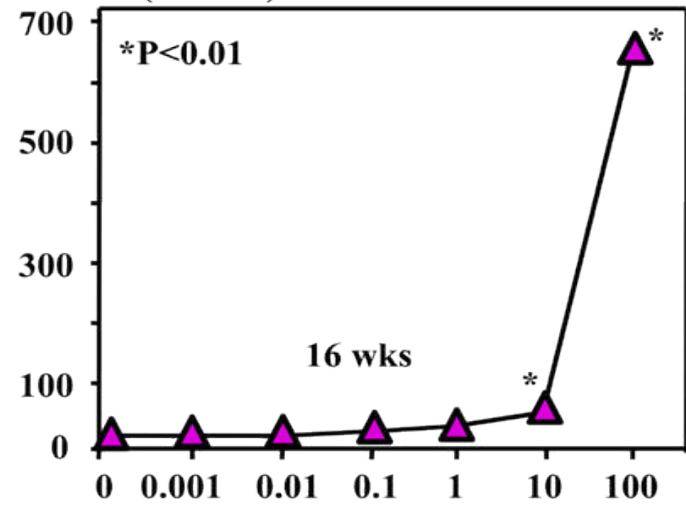

MeIQx dose (ppm in diet)

$\mathbf{E}$

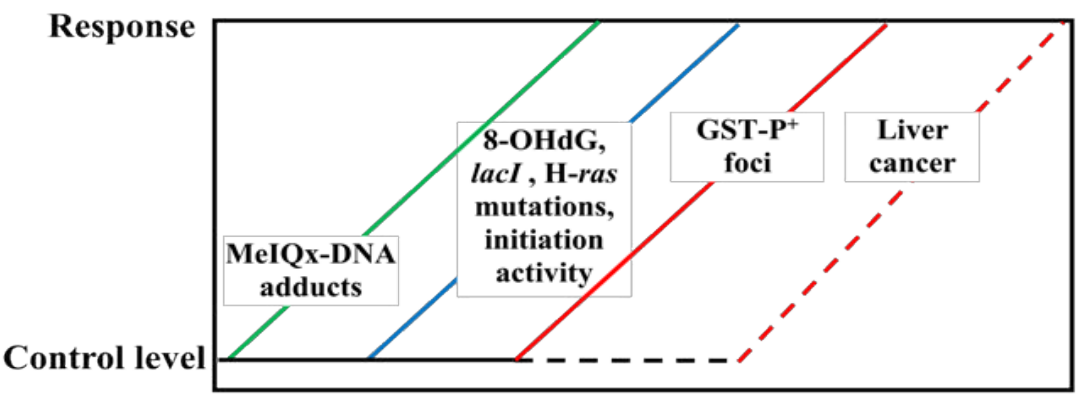

MeIQx doses

Figure 1: Hepatocarcinogenicity of MelQx in rats. Male F344 rats were treated with MelQx at wide range of doses for 2,4,16 and 32 weeks for the examination of GST-P $^{+}$foci development (A), MelQx adducts (B) and 8-OHdG formation in DNA (C). (D) Incidence of lacl gene mutations and development of GST-P+ foci was detected in the liver of Big Blue rats treated with MelQx for 16 weeks. (E) Reaction curves for the carcinogenicity markers dependent on the dose of MelQx exposure.

This is an illustration for MelQx effects in log-log scale.

concurrent treatment with low carcinogenic doses of these 2 carcinogens did not show additive or synergistic effects. However, in case of co-administration of MeIQx and DEN at high carcinogenic doses synergetic effects were found. Thus, the existence of no-effect levels of combinations of MeIQx and DEN was demonstrated, which provided new evidence for the idea of existence of a threshold for the carcinogenicities of genotoxic carcinogens.

The carcinogenic potential of MeIQx at low doses and the human 
relevance was further investigated in a 2-year carcinogenicity test using male F344 rats, which were administered MeIQx-containing diet at doses of 0 (control), $0.001,1$, and $100 \mathrm{ppm}$ [24]. Histopathological analysis demonstrated the significant induction of hepatocellular carcinomas, adenomas and development of GST- $\mathrm{P}^{+}$foci by the treatment with 100 ppm MeIQx. However, no effect on altered preneoplastic hepatocellular foci was observed in 0.001 and 1 ppm groups. 8-OHdG levels in the rat liver DNA in $100 \mathrm{ppm}$-treated rats livers were not elevated, but MeIQxDNA adduct formation increased as compared with the $1 \mathrm{ppm}$ case, albeit without significance. It was concluded that $1 \mathrm{ppm}$ dose may be a no-effect level for MeIQx hepatocarcinogenicity.

Through the investigation of MeIQx effects after application at various doses at in rat hepatocarcinogenesis, the sequence of events was found to occur in the liver: first, the induction of DNA-MeIQx adducts at low doses, then an increase of DNA 8-OHdG formation and rise in lacI gene mutations with increase of the dose level, and next, due to the strengthening of MeIQx initiation activity, induction of development of the rat liver preneoplastic lesions $\left(\mathrm{GST}^{-\mathrm{P}^{+}}\right.$foci) at high doses. From these data, the existence of the no-effect levels for the examined markers, which are indicators of hepatocarcinogenesis, has been proven. The different quantitative levels for the effects of each marker were detected, and according to the qualitative assessment on the basis of carcinogenicity mechanisms, it has been concluded that MeIQx has a threshold, at least a practical one, for its hepatocarcinogenicity in the rat liver.

\section{Carcinogenicity of 2-amino-3-methylimidazo[4,5- $f]$ quino- line (IQ) in the rat liver}

IQ is one of the genotoxic and carcinogenic HCAs formed by hightemperature cooking of proteinaceous food, which targets multiple organs in rodents. Thus, long-term treatment with $300 \mathrm{ppm}$ IQ has been shown to induce tumors in the liver, small and large intestines, Zymbal gland, clitoral gland, skin, mammary gland, the ear duct, lung, pancreas and bladder of rats [25-27].The mutagenicity and carcinogenicity of IQ are considered initially to involve oxidation of the exocyclic amino group $(\mathrm{G})$ to its corresponding N-hydroxyl-IQ by liver CYP1A1 and CYP1A2, resulting in formation of DNA adducts, and mutations leading to the neoplastic transformation [28].

The carcinogenicity of low doses of IQ and its mechanisms were investigated in 1595 male F344 rats administered with IQ at doses of $0,0.001,0.01,0.1,1,10$ and $100 \mathrm{ppm}$ in the diet for 16 weeks. Treatment with doses of $1 \mathrm{ppm}$ and below did not induce GST-P ${ }^{+}$ foci in the liver, while 10 and $100 \mathrm{ppm}$ doses application resulted in their development. Thus, the presence of no-effect levels of IQ for the liver carcinogenicity in the rat was demonstrated. The mechanism was proposed to be related to significant up-regulation of $\mathrm{p} 21^{\mathrm{WAF} 1 / \mathrm{Cip}}$ by IQ at doses below those required for its mediated carcinogenic effect in the liver. It has been suggested that suppression of cell cycle progression by $\mathrm{p} 21^{\mathrm{WAF} 1 / \mathrm{Cip}}$ followed by DNA repair is at least one of the mechanisms responsible for the observed no effect of low doses of IQ in rats in this model. Furthermore, IQ administration at doses of 0.01-10 ppm induced elevation of IQ metabolizing enzyme CYP1A2, while $100 \mathrm{ppm}$ IQ caused up-regulation of CYP1A1 rather than CYP1A2. Significant induction of APE-1 and GADD45 was observed only at the highest doses of 10 and or $100 \mathrm{ppm}$, thus indicating that the IQ-induced DNA damage response is dose-dependent (Figures 2A and 2B)

\section{Carcinogenicity of 2-amino-1-methyl-6-phenylimidazo[4,5- b] pyridine (PhIP) in the rat colon}

A heterocyclic amine, PhIP, has attracted particular attention as a potential human colon genotoxic carcinogen, as humans are in fact exposed to continuous low doses of HCAs during lifetime. PhIP was shown to be metabolized by CYP1A2 [29], and to exert carcinogenicity in the rat colon [30].Furthermore, recent data indicated that PhIP could cause stomach injury, oxidative stress in rat stomach as well as the activation of $\mathrm{c}$-fos and c-jun and inactivation of p16, which may play a role in the pathogenesis of PhIP-associated stomach cancer [31]. Moreover, PhIP induced signal transducer and activator of transcription 1 (Stat1) and vascular endothelial growth factor (VEGF) expression which was suggested to be involved in PhIP-enhanced colon tumorigenesis in the post-initiation phase [32] (Table 1) (Figure 3). Furthermore, recent studies reported that down-regulation of breast cancer resistance protein (BCRP) expression in murine colon adenomas leads to an accumulation of PhIP in the above-mentioned lesions [33], thus suggesting that BCRP is an important PhIP efflux transporter.

To investigate carcinogenicity of PhIP in the rat colon, 1920, 6-week-old F344 male rats were administered carcinogen at a range of doses from 0.001 (human exposure level) to $400 \mathrm{ppm}$ in their diet for 16 weeks [34]. The development of aberrant crypt foci (ACF), which are considered as a surrogate marker of the preneoplastic lesions in the colon [35], was not altered by PhIP application at doses of 0.001 to $10 \mathrm{ppm}$, however, at the doses of 50 to $400 \mathrm{ppm}$ a significant increase in their number was observed (Figure 4 and Table 1). Furthermore, significant elevation of PhIP-DNA adduct level was detected in the groups treated with doses of $0.01 \mathrm{ppm}$ and higher.

Next, we focused on the carcinogenicity of PhIP in the rat large intestine at various dose levels in initiation and promotion models of carcinogenesis. A total of 1926-week-old male F344 rats were subcutaneously injected twice with $15 \mathrm{mg} / \mathrm{kg}$ body weight azoxymethane (AOM), then continuously fed various doses $(0,0.001$,

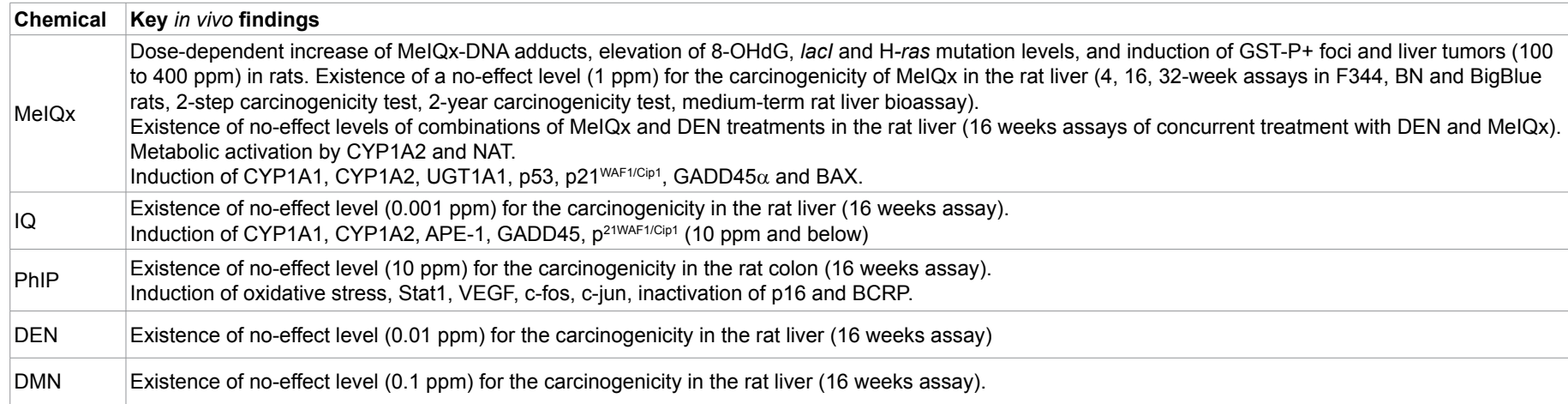

Table 1: Key in vivo findings observed with several genotoxic carcinogens.. 

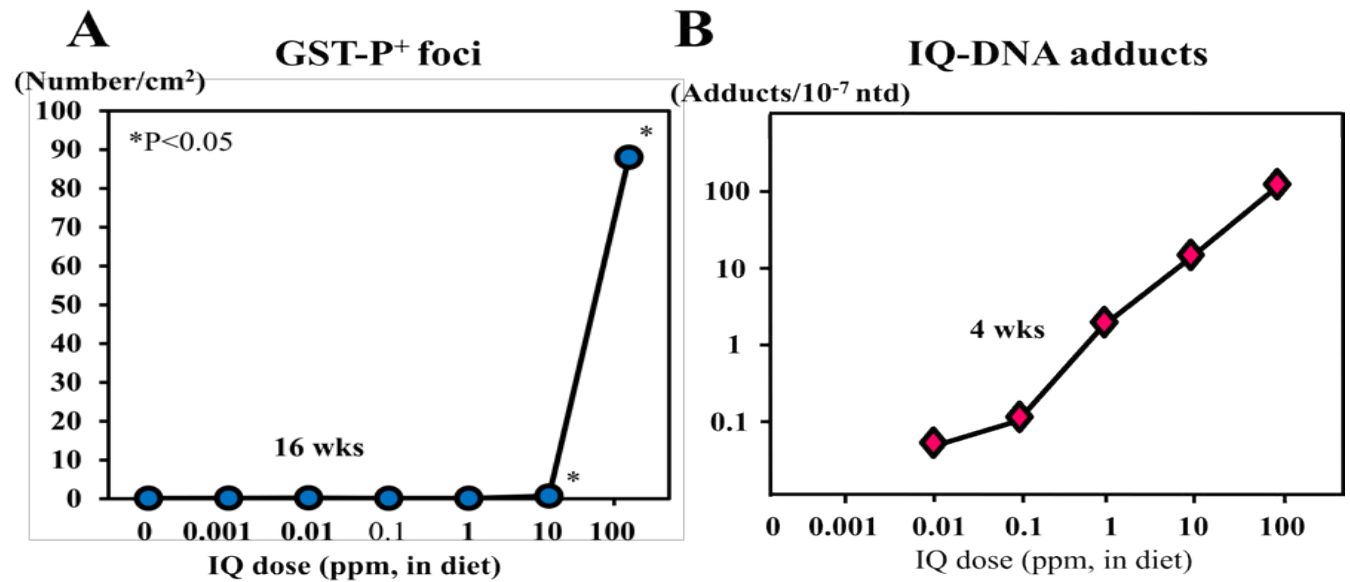

Figure 2: Effects of IQ on development of GST-P+ foci (A) and IQ-DNA adduct formation (B) in the livers of F344 rats administered IQ for 16 weeks in the diet. IQ-DNA adduct levels for IQ doses of 0 and $0.001 \mathrm{ppm}$ are under detection limit.

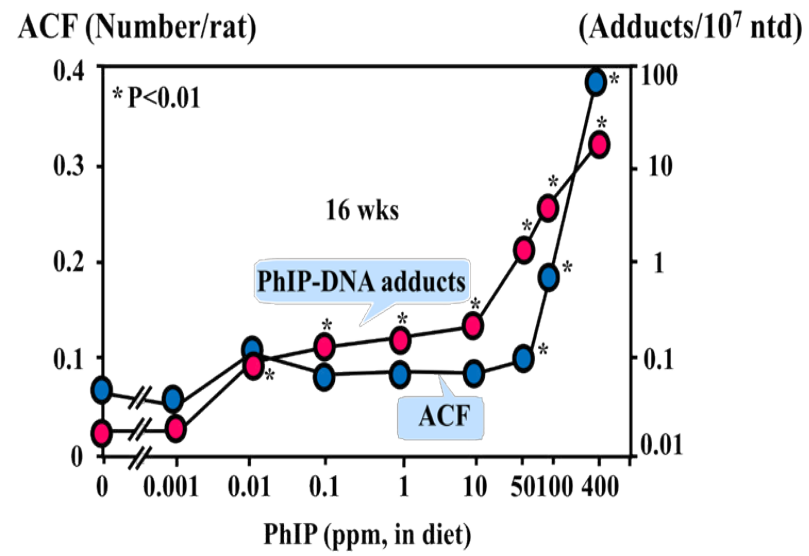

Figure 3: Shows the vegetal cover to protect the headward erosion during concentrted flow.

$0.01,0.1,1,10,50$ and $200 \mathrm{ppm}$ ) of PhIP in the diet up to 16 and 36 weeks for the analysis of ACF and colon tumors (36). PhIP was found to enhance strongly AOM-initiated rat large intestinal tumorigenesis at high doses (50 and 200 ppm), while lower doses (0.001-10 ppm) had no apparent effects. High doses also caused variation in tumor histological types and their distribution throughout the large intestinal segments. Frequencies of $\mathrm{ACF} / \mathrm{cm}^{2}$ did not meaningfully vary between the groups. Cellular proliferation activity in normal-appearing colonic mucosa was significantly increased at high doses. These findings provided new evidence of a low-dose potential for PhIP, with a no-effect level to be 10 ppm in this initiation-promotion experimental model [36]

\section{Hepatocarcinogenicity of $\mathrm{N}$-nitrosocompounds in rats}

Typical rodent hepatocarcinogens, N-nitrosocompounds (e.g. DEN and dimethylnitrosamine (DMN)) which mode of action is still unclear, have been shown to be synthesized in the stomach through the reaction of secondary amines and nitrites. Furthermore, they are contained in different life-substances and known as contaminants of different natural and manufactured food products. Metabolic oxidation of dialkylnitrosamines, during which they are activated and transformed into direct-acting mutagens, is known to carry out by two systems: one utilizes porphyrin and oxidant as a model for shunt pathway in the metabolizing pathway of cytochrome P450, and the other one utilizes Fenton reagent [37].

The carcinogenicity of DEN with respect to the relationship between the applied dose and reactivity was investigated by Peto and colleagues using 4080 male rats [38]. DEN at doses of 0.033 to 13.896 ppm was administered to rats in their drinking water, and induction of liver cancer was found to be dependent on the applied dose of DEN. Therefore, from the existence of the relationship between the treatment dose and tumorigenicity, it was concluded that DEN had no threshold for its carcinogenicity in the rat liver. However, as it has been noticed that experimentally examined low dose levels are still high as compared to the levels of human exposure, for clarification of the existence of the threshold in DEN hepatocarcinogenicity, we have decided to examine the influence of DEN applied at lower doses than those used by Peto et al. [38]. The doses of DEN and DMN were established in animal studies with reference to the human daily exposure which is about $0.0001 \mathrm{ppm}$ $[39,40]$.

Thus, in our next study, to investigate the carcinogenicity of low doses of DEN in the rat liver, 2000, 21-day-old male F344 rats were administered DEN over a range of doses from 0.0001 to $1 \mathrm{ppm}$ in their drinking water for 16 weeks (Table 1 and Figure 4) [17]. No induction of GST-P+ foci was observed at DEN doses of 0 to $0.01 \mathrm{ppm}$, however, their values were significantly elevated at doses of $0.1 \mathrm{ppm}$ or higher, demonstrating the no-effect level for DEN hepatocarcinogenicity.

When the hepatocarcinogenicity of another $\mathrm{N}$-nitrosocompound, DMN, was examined using the same experimental assay, in which the carcinogen was applied to F344 rats at doses of 0.0001 to $10 \mathrm{ppm}$ in their drinking water for 16 weeks, no induction of GST-P ${ }^{+}$foci was found at doses of 0.001 to $0.1 \mathrm{ppm}$, but the significant increase of their numbers and areas was observed at 1 and $10 \mathrm{ppm}$ (Table 1 and Figure 4) [41]. It was concluded that similarly to DEN, DMN has no-effect level for its hepatocarcinogenicity in rats.

\section{Conclusion}

Our recent data on the effects of DNA reactive genotoxic carcinogens such as HCAs, MeIQx, IQ and PhIP, and N-nitrosocompounds, DEN 
A

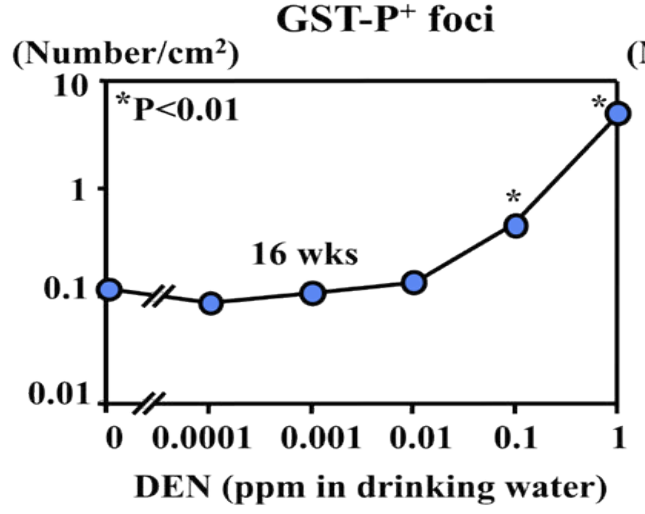

B

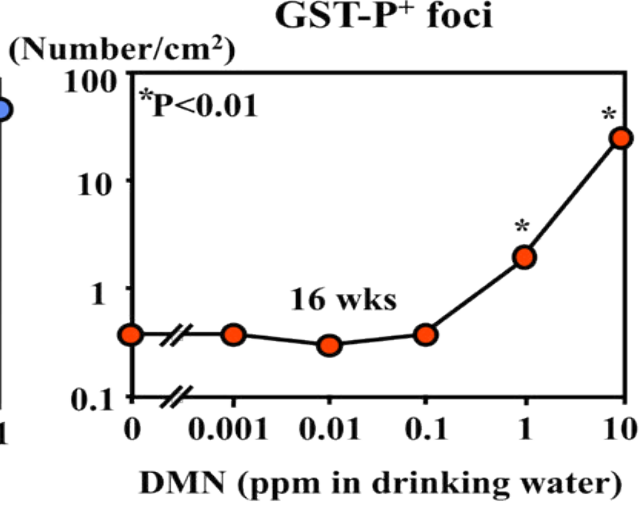

Figure 4: Hepatocarcinogenicity of $\mathrm{N}$-nitrosocompounds in the rat liver. Rats were treated with DEN (A) and DMN (B) at different doses for 16 weeks for the assessment of GST-P+ foci development.

and DMN, in animal models indicate the existence of threshold, at least practical, with respect to their carcinogenicity, which implies the maintenance of homeostasis, with adaptive responses involving alteration to formation of DNA damage, DNA adducts, gene alteration and repair, apoptosis, cell proliferation and cell signaling. This conclusion is very important regarding how we should view the impact of genotoxic carcinogens in human environment in relation to cancer risk assessment and management. Genotoxic carcinogens (e.g. MeIQx), are suggested first to induce formation of DNA adducts at low doses, then elevation of 8-OHdG formation levels in DNA and rise in gene mutations at higher doses, followed by induction of preneoplastic lesions at high doses. The primary importance of formation of DNA adducts by genotoxic chemicals, which contributes to the initiation stage of carcinogenesis is pointed out. Furthermore, formation of oxidative stress might be a secondary mechanism for the carcinogenicities of genotoxic chemical carcinogens which is likely to be implicated in promotion and progression stages of chemical carcinogenesis.

\section{Conflict of Interest}

The authors declare no conflict of interest.

\section{Acknowledgement}

These studies were supported by a grant from the Japan Science and Technology Corporation, included in the Project of Core Research for Evolutional Science and Technology (CREST) and by a grant from the Ministry of Education, Culture, Sports, Science and Technology of Japan.

\section{References}

1. Pollycove M, Feinendegen LE (2001) Biologic responses to low doses of ionizing radiation: Detriment versus hormesis. Part 2. Dose responses of organisms. J Nucl Med 42: 26N-32N, 37N.

2. Williams GM, latropoulos MJ (2002) Alteration of liver cell function and proliferation: differentiation between adaptation and toxicity. Toxicol Pathol 30: 41-53.

3. Morgan WF (2011) Communicating non-targeted effects of ionizing radiation to achieve adaptive homeostasis in tissues. Curr Mol Pharmacol 4: 135-140.

4. Kuraoka I (2008) Effects of DNA lesions on transcription elongation by RNA polymerases. Genes and Environment 30: 63-70.

5. Bailey GS, Dashwood R, Loveland PM, Pereira C, Hendricks JD (1998) Molecular dosimetry in fish: quantitative target organ DNA adduction and hepatocarcinogenicity for four aflatoxins by two exposure routes in rainbow trout. Mutat Res 399: 233-244.
6. Kasai H (1997) Analysis of a form of oxidative DNA damage, 8-hydroxy-2'deoxyguanosine, as a marker of cellular oxidative stress during carcinogenesis Mutat Res 387: 147-163.

7. Kato T, Ohgaki H, Hasegawa H, Sato S, Takayama S, etal. (1988) Carcinogenicity in rats of a mutagenic compound, 2-amino-3,8-dimethylimidazo[4,5-f] quinoxaline. Carcinogenesis 9: 71-3.

8. Nakagama H, Nakanishi M, Ochiai M (2005) Modeling human colon cancer in rodents using a food-borne carcinogen, PhIP. Cancer Sci 96: 627-636.

9. Snyderwine EG, Venugopal M, Yu M (2002) Mammary gland carcinogenesis by food-derived heterocyclic amines and studies on the mechanisms of carcinogenesis of 2-amino-1-methyl-6-phenylimidazo[4,5-b]pyridine (PhIP). Mutat Res 506-507: 145-52.

10. Sugimura T (1995) History, present and future, of heterocyclic amines, cooked food mutagens. Princess Takamatsu Symp 23: 214-231.

11. Sugimura $T(2000)$ Nutrition and dietary carcinogens. Carcinogenesis $21: 387-395$

12. Totsuka Y, Fukutome K, Takahashi M, Takahashi S, Tada A, et al. (1996) Presence of N2-(deoxyguanosin-8-yl)-2-amino-3,8-dimethylimidazo[4,5-f] quinoxaline (dG-C8-MelQx) in human tissues. Carcinogenesis 17: 1029-1034.

13. Szterk A1, Waszkiewicz-Robak B2 (2013) Influence of selected quality factors of beef on the profile and the quantity of heterocyclic aromatic amines during processing at high temperature. Meat Sci 96: 1177-1184.

14. Szterk A, Roszko M, Małek K, Kurek M, Zbieć M, et al. (2012) Profiles and concentrations of heterocyclic aromatic amines formed in beef during various heat treatments depend on the time of ripening and muscle type. Meat Sci 92 587-595.

15. Szterk A (2013) Chemical state of heterocyclic aromatic amines in grilled beef: evaluation by in vitro digestion model and comparison of alkaline hydrolysis and organic solvent for extraction. Food Chem Toxicol 62: 653-660.

16. Pezdirc M, Zegura B, Filipič M (2013) Genotoxicity and induction of DNA damage responsive genes by food-borne heterocyclic aromatic amines in human hepatoma HepG2 cells. Food Chem Toxicol 59: 386-394.

17. Fukushima S, Wanibuchi H, Morimura K, Wei M, Nakae D, et al. (2002) Lack of a dose-response relationship for carcinogenicity in the rat liver with low doses of 2-amino-3,8-dimethylimidazo[4,5-f]quinoxaline or $\mathrm{N}$-nitrosodiethylamine. Jpn J Cancer Res 93: 1076-1082.

18. Fukushima S, Wei M, Kakehashi A, Wanibuchi H (2010) Thresholds for genotoxic carcinogens: Evidence from mechanism-based carcinogenicity studies. In Hsu C-H and Stedeford T (ed.), Cancer Risk Assessment: Chemical Carcinogenesis, Hazard Evaluation, and Risk Quantification. John Wiley \& Sons Inc., Hoboken, USA, 207-222.

19. Yano Y, Yano T, Kinoshita A, Matoba A, Hasuma T, et al. (2010) Sensitive quantitative assay for point mutations in the rat $\mathrm{H}$-ras gene based on single nucleotide primer extension. Exp Ther Med 1: 657-661. 
Citation: Kakehashi A, Fukushima S, Wei M, Wanibuchi H (2014) Threshold in Carcinogenicity of Genotoxic Carcinogens. J Carcinog Mutagen S3: 006. doi:10.4172/2157-2518.S3-006

20. Hoshi M, Morimura K, Wanibuchi H, Wei M, Okochi E, et al. (2004) No-observed effect levels for carcinogenicity and for in vivo mutagenicity of a genotoxic carcinogen. Toxicol Sci 81: 273-279.

21. Fukushima S, Wanibuchi $H$, Morimura K, Wei M, Nakae D, et al. (2003) Lack of initiation activity in rat liver of low doses of 2-amino-3,8-dimethylimidazo[4,5-f] quinoxaline. Cancer Lett 191: 35-40.

22. Wei M, Hori TA, Ichihara T, Wanibuchi H, Morimura K, et al. (2006) Existence of no-observed effect levels for 2-amino-3,8-dimethylimidazo[4,5-f]quinoxaline on hepatic preneoplastic lesion development in BN rats. Cancer Lett 231: 304-308.

23. Wei M, Kakehashi A, Yamano S, Tamano S, Shirai T, et al. (2012) Lack of Hepatocarcinogenicity of Combinations of Low Doses of 2-amino-3, 8-dimethylimidazo[4,5- $\mathrm{f}$ ]quinoxaline and Diethylnitrosamine in Rats: Indication for the Existence of a Threshold for Genotoxic Carcinogens. J Toxicol Patho 25: 209-214

24. Murai T, Mori S, Kang JS, Morimura K, Wanibuchi H, et al. (2008) Evidence of a threshold-effect for 2-amino-3,8-dimethylimidazo-[4,5-f]quinoxaline liver carcinogenicity in F344/DuCrj rats. Toxicol Pathol 36: 472-477.

25. Kitamura Y, Umemura T, Okazaki K, Kanki K, Imazawa T, et al. (2006) Enhancing effects of simultaneous treatment with sodium nitrite on 2-amino-3-methylimidazo[4,5-f]quinoline-induced rat liver, colon and Zymbal's gland carcinogenesis after initiation with diethylnitrosamine and 1,2-dimethylhydrazine. Int J Cancer 118: 2399-404.

26. Ohgaki H, Hasegawa H, Kato T, Suenaga M, Sato S, et al. (1985) Carcinogenicities in mice and rats of $I Q, M e I Q$, and MeIQx. Princess Takamatsu Symp 16: 97-105.

27. Weisburger JH, Barnes WS, Lovelette CA, Tong C, Tanaka T, et al. (1986) Genotoxicity, carcinogenicity, and mode of action of the fried food mutagen 2-amino-3-methylimidazo[4,5-f]quinoline (IQ). Environ Health Perspect 67 : 121-127.

28. Hammons GJ, Milton D, Stepps K, Guengerich FP, Tukey RH, et al. (1997) Metabolism of carcinogenic heterocyclic and aromatic amines by recombinant human cytochrome P450 enzymes. Carcinogenesis 18: 851-854.

29. Chen C, Ma X, Malfatti MA, Krausz KW, Kimura S, et al. (2007)A comprehensive investigation of 2-amino-1-methyl-6-phenylimidazo[4,5-b]pyridine (PhIP) metabolism in the mouse using a multivariate data analysis approach. Chem Res Toxicol 20: 531-542.

30. Ito N, Hasegawa R, Sano M, Tamano S, Esumi H, et al. (1991) A new colon and mammary carcinogen in cooked food, 2-amino-1-methyl-6-phenylimidazo[4,5-b] pyridine (PhIP). Carcinogenesis 12: 1503-1506.
31. Li R, Tian J, Li W, Xie J (2013) Effects of 2-amino-1-methyl-6-phenylimidazo [4,5-b] pyridine (PhIP) on histopathology, oxidative stress, and expression of c-fos, c-jun and p16 in rat stomachs. Food Chem Toxicol 55: 182-191.

32. Doi K, Hagihara A, Wei M, Yunoki T, Fukushima S, et al. (2007) Altered gene expression in rat colonic adenocarcinomas induced in an azoxymethane plus 2-amino-1-methyl-6-phenylimidazo[4,5-b]- pyridine initiation-promotion model. Oncology 73: 252-260.

33. Dietrich CG, Vehr AK, Martin IV, Gassler N, Rath T, et al. (2011) Downregulation of breast cancer resistance protein in colon adenomas reduces cellular xenobiotic resistance and leads to accumulation of a food-derived carcinogen. Int J Cancer 129: 546-552.

34. Fukushima S, Wanibuchi H, Morimura K, Iwai S, Nakae D, et al. (2004) Existence of a threshold for induction of aberrant crypt foci in the rat colon with low doses of 2-amino-1-methyl-6-phenolimidazo[4,5-b]pyridine. Toxicol Sci 80 109-114.

35. Takahashi S, Ogawa K, Ohshima H, Esumi H, Ito N, et al. (1991) Induction of aberrant crypt foci in the large intestine of F344 rats by oral administration of 2-amino-1-methyl-6-phenylimidazo[4,5-b]pyridine. Jpn J Cancer Res 82: 135-137.

36. Doi K, Wanibuchi H, Salim El, Morimura K, Kinoshita A, et al. (2005) Lack of large intestinal carcinogenicity of 2-amino-1-methyl-6-phenylimidazo[4,5-b] pyridine at low doses in rats initiated with azoxymethane. Int $\mathrm{J}$ Cancer 115 870-878.

37. Mochizuki M (2000) [Activation of environmental carcinogenic $\mathrm{N}$-nitrosodialkylamines by model systems for metabolic oxidation]. Yakugaku Zasshi 120: 997-1005.

38. Peto R, Gray R, Brantom P, Grasso P (1991) Effects on 4080 rats of chronic ingestion of $\mathrm{N}$-nitrosodiethylamine or $\mathrm{N}$-nitrosodimethylamine: a detailed doseresponse study. Cancer Res 51: 6415-6451.

39. Bartsch H, Montesano R (1984) Relevance of nitrosamines to human cancer Carcinogenesis 5: 1381-1393.

40. Spiegelhalder B, Preussmann R (1983) Occupational nitrosamine exposure. 1. Rubber and tyre industry. Carcinogenesis 4: 1147-1152.

41. Fukushima S, Wanibuchi H, Morimura K, Nakae D, Tsuda H, et al. (2005) Lack of potential of low dose $\mathrm{N}$-nitrosodimethylamine to induce preneoplastic lesions, glutathione S-transferase placental form-positive foci, in rat liver Cancer Lett 222: 11-15.

This article was originally published in a special issue, DNA damage/ repair: Mutagenesis : Carcinogenesis handled by Editor(s). Dr. Lubomir Manolov Stoilov, University: Institute of Genetics, Bulgaria; Dr. Kandace Jo Williams, University of Toledo College of Medicine, USA; Dr. Mu Wang, Indiana University School of Medicine, USA 